\title{
Brouhaha among the breadfruit
}

\author{
Paula Brown Glick
}

Margaret Mead and Samoa: The Making and Unmaking of an Anthropological Myth. By Derek Freeman.

Harvard University Press: 1983. Pp.379. \$20, f11.95.

FIFTY-five years after the publication of Coming of Age in Samoa, Derek Freeman has written this book to demonstrate that Margaret Mead's account of Samoan culture is "fundamentally in error", that she is incorrect in nearly everything she wrote about Samoa. The criticism is especially directed to Coming of Age in Samoa, but also refutes many of her statements in articles and in another of her books, Social Organization of Manu'a. Freeman's persuasive writing combines quotations from historical and ethnographic reports on Samoa with his own field research, documentary study in Samoa - including police and court records - and conversations with Samoans. He quotes anthropologists, psychologists and biologists on general issues, and makes extensive use of the writings of Margaret Mead, including her autobiography, Blackberry Winter, and Letters from the Field.

The book's publication was heralded by newspaper and magazine articles, radio and television appearances, as may be appropriate to Mead's standing and influence in the United States. In the years following her work in Samoa she conducted many other studies. She was a leader in techniques of observation, filming and recording behaviour. Her written work, as catalogued at New York's American Museum of Natural History where she worked throughout her life, runs to 1,597 items. Mead held a high position in American scholarship, received many awards and honours, was elected to distinguished scientific bodies. To her last days she made major speeches at scientific meetings. Throughout this time, she was in continuing demand as a public speaker, interviewed and quoted, wrote popular articles and magazine columns. She was the best known and most influential social scientist in America.

Freeman, now Professor Emeritus of Anthropology in the Research School of Pacific Studies at the Australian National University, has long been respected for his scholarship, particularly for his work on the Iban of Sarawak, who were the subjects of a study he conducted in 1949 and 1950 . His essay "On the Concept of the Kindred" won the Curl Bequest Prize of the Royal Anthropological Institute in 1960. A New Zealander, he conducted research in Samoa in the 1940s and made a series of later visits, the last in 1981. In the preface, he tells of a meeting with Mead in 1964, in

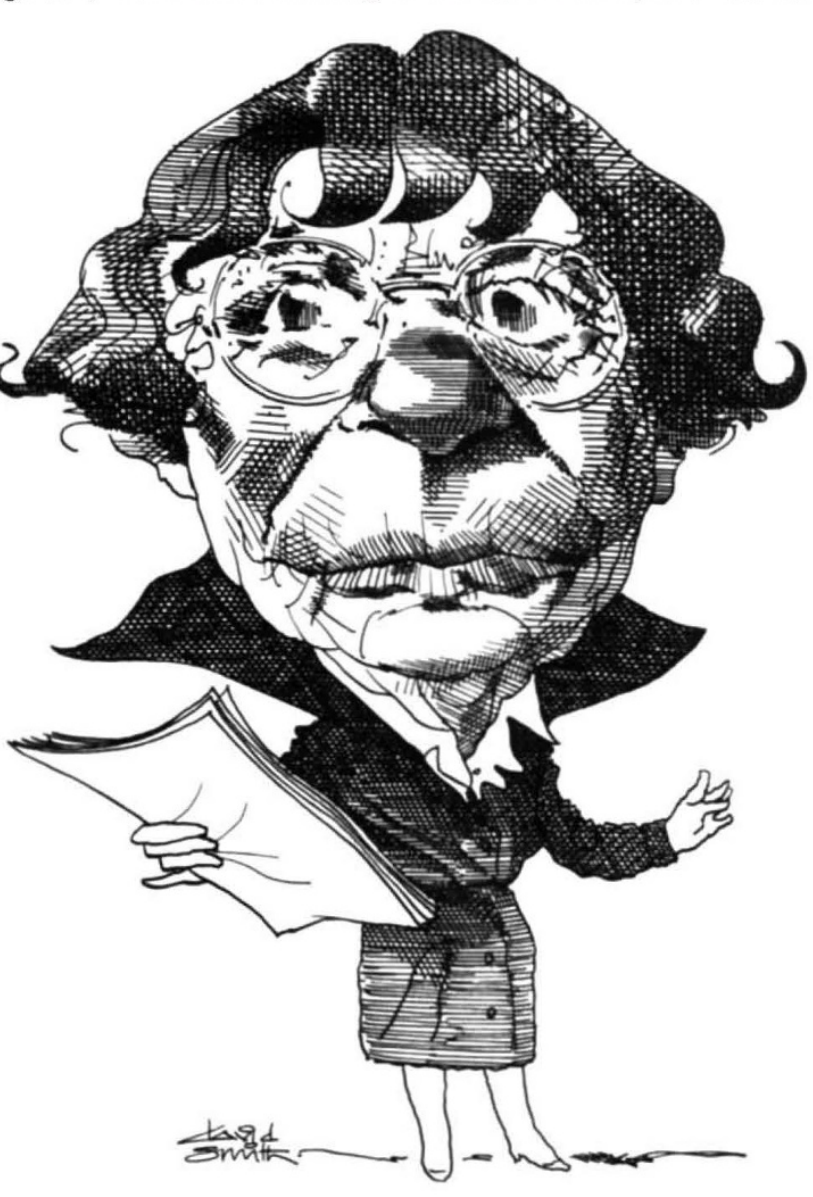

which he told her of his disagreement with her findings. He says that shortly before her death in 1978, he wrote, offering to send her a draft of his conclusions. His investigations have extended over 40 years, including six years in Samoa and even longer in research libraries. The documentation in his book is thorough: 55 pages of footnotes and many references to his own inquiries in Samoa.

Why should Freeman, a respected senior scholar, devote years of painstaking research to demonstrate that Mead's books and articles published over 50 years ago are false? There could be several answers, one of which is his championing of the biological bases of human behaviour.

Freeman begins his book with a discussion of American anthropology in the 1920s. Franz Boas of Columbia University, then the leader of American cultural anthropology, was a strong advocate of cultural determinants of behaviour. Margaret Mead was his student. Early chapters describe an academic intrigue: Boas sent Mead into the field to prove his position in the nature-nurture controversy of the 1920s. Boas hoped to convince social and behavioural scientists of the time that culture is the dominant influence in personal development, with evidence from Samoa that adolescence need not represent a period of crisis or stress. In directing Mead's Samoan research Boas instructed her to concentrate upon adolescent girls, not to do a full ethnography of Samoa. She spent nine months in Tutuila and Manu'a, American Samoa. Immediately upon her return, Mead wrote Coming of Age in Samoa, which became an all-time bestseller, going through numerous editions and translations, and being assigned to countless undergraduates, quoted and expanded upon by other social and behavioural scientists; the book is still found in nearly every American library and bookstore.

To Freeman, Mead's Samoan research became the basis of an anthropological myth, which denies any role to biology or human nature in accounting for adolescent stress and human behaviour. In the $1920 \mathrm{~s}$ Malinowski and RadcliffeBrown, in Great Britain and the Commonwealth, were beginning to draw up the anthropological approach which has become known as "structuralfunctionalism". This holistic viewpoint aims to demonstrate the interconnections of activities and institutions within a social system. However, they had not yet had much impact in the United States. Culture, the particular beliefs and practices of people, remained of dominant interest in American anthropology. After the death of Boas in 1942, and of Ruth Benedict in 1949, Mead carried the ideas of cultural anthropology in her writings and speeches to an ever-wider public.

While Freeman's concluding chapter returns to the theme of biological influence on behaviour, the major part of the book details his objection to Mead's statements about Samoa. Repeatedly Freeman makes such statements as:

In the chapters that follow evidence will be adduced to show that the main conclusions of Coming of Age in Samoa are, in reality, the figments of an anthropological myth, which is 
deeply at variance with the facts of Samoan ethnography and history [p.109].

However, the data sources and evidence presented by Mead and Freeman are quite different. Mead, then 23, worked with adolescent and pre-adolescent girls in three villages in Manu'a. In an appendix she presented data sheets for the analysis of girls' age, family and social position, and behaviour. She described adolescence as the best period of a woman's life, without stress or conflict, preoccupied with sex and lovemaking. Mead contrasted the gentle and carefree adolescence of Samoans with the educational and social pressures upon American youth, urging America to be less demanding of its young.

Freeman goes to great lengths to disprove Mead's characterization of Samoan adolescence. To establish that Samoan youths have a similar pattern of violence to that in other countries, he cites court records of Western Samoa, for 1967, which show that males in the age-group 14-20 constitute a high proportion of first offenders. It is as though observations of teenagers in a village such as Lower Slaughter in 1925 are disproved by Birmingham police records for 1967. Freeman says,

Mead, then, was at error in her depiction of the nature of adolescence in Samoa, just as she was

. in her portrayal of other crucial aspects of Samoan life. This being so, her assertion in Coming of Age in Samoa of the absolute sovereignty of culture over biology, on the basis of these erroneous depictions, is clearly invalid, and her much-bruited "negative instance" is seen to have been no negative instance at all. In other words, Mead's presentation of Samoa as proving the insignificance of biology in the etiology of adolescent behavior is revealed as a false case [p.268].

Freeman's critique includes the complaint that Mead never returned to Samoa, nor revised her books on the basis of later studies. In response to this, Mead speaks for herself in the preface to the 1973 edition of Coming of Age in Samoa:

Some young critics have even asked me when I am going to revise this book, and look unbelieving and angry when I say that to revise it would be impossible. It must remain, as all anthropological works must remain, exactly as it was written, true to what I saw in Samoa, and of what I was able to convey of what I saw. True to the state of our knowledge of human behavior as it was in the mid-1920s, true to our hopes and fears for the future of the world [p.x].

Further, Mead clearly acknowledged the importance of the work of others, including Freeman, in her conclusion to the reissued Social Organization of Manu'a in 1969:

Then, in 1965, I met Derek Freeman for the first time, and he challenged my material on the very mild Manu'an reactions I had reported on the

*The "negative instance" is defined by Freeman as Boas's view of scientific method in which a single negative case invalidates a hypothesis. In fact, Freeman dedicates his book to Karl Popper because of Popper's work on scientific method. subject of virginity. He cited intense feeling about virginity on the part of mothers of girls, and extreme preoccupation with the theft of girls in other villages on the part of young men in western Samoa. In thinking this over, I realized for the first time that the whole of the rivalry between the young men or the chiefs of different villages, could be expressed in the hope of one group that they could do irreparable, asymmetrical damage to the other group.... Translated into terms of behavior, it accounts for the continuous wariness and touchiness which Samoans display in several contexts ever alert lest something one would enjoy doing to others be done to oneself .

We need much more detailed material on early childhood, material which hopefully Derek Freeman's current fieldwork will provide [p.227].

The very nature of ethnographic field work, as a local study by a lone anthropologist, raises questions about reliability and generalization. The field worker pursues particular subjects and problems, chooses a community, works closely with only some members of that community, and publishes observations and conclusions based upon the fieldwork and the information available from other sources. Subsequent research among the same people - in this case an island group with a population of over $150,000-$ is likely to find differences attributable to local conditions, historical changes, and interpretation or emphasis. Certainly ambiva-

\section{Little room for the anthropologist}

\section{Mary Douglas}

Margaret Mead: A Voice for the

Century.

By Robert Cassidy.

Universe Books: 1982. Pp.176. \$12.50.

MARGARET Mead, born into an academic family in Philadelphia in 1901, died internationally famous and loaded with honours in 1978. Her remarkable life deserves to be recorded and reflected upon. She was an anthropologist, a teacher, a humanitarian, a popular writer, a media star and a lay preacher. Her record defies classification but it invites a more reflective treatment than is here provided by Robert Cassidy. His book suffers the usual limitations of hagiography, strong in praise of the deceased and weak in dealing with the enigmas and problems of a person living in a particular place and time. We are left with hints - apparently fellow ethnologists accorded her only "grudging admiration" and her success was definitely in the larger community, "grandmother to America", "citizen of the world" or "voice for the century".

Her graduate work was in the University of Columbia, with Franz Boas and Ruth Benedict. Boas was building up a new lences and contradictions characterize every society. Conflicting findings are sometimes taken as evidence that anthropological research is both subjective and unreliable. And while Freeman presents much evidence to contradict Mead's statements, he cannot claim to have reproduced her conditions of field work with adolescent girls in Manu'a in 1925. His contention that she was innocently duped and misled by village girls is unwarranted.

Why, one wonders, has not Freeman written a new book on Samoa which incorporates the results of his researches, rather than a series of chapters devoted to Mead's "errors"? He amply demonstrates his ability to describe the social, political and rank system of Samoa in a way that summarizes his research and that of many other scholars into a clear and consistent statement. One can only surmise that his was personal preference for criticism over construction. By this choice, he has prevented anthropologists from evaluating the potential of his biological explanation of Samoan behaviour. Mead's work will continue to reflect its time and place, but Freeman has yet to demonstrate the correctness of his position.

Paula Brown Glick is Professor of Anthropology at the State University of New York, Stony Brook. She is author of Highland Peoples of New Guinea (Cambridge University Press, 1978).

science of anthropology, specially focused on the relationship between the invidual and culture and on methods of assessing that relationship. Cassidy's account of how Boas set the theoretical problems of her fieldwork project does not quite ring true. That towering scholar, geologist, physicist, organizer of great Arctic and north American expeditions, apparently first drew her attention to the cultural variation in sexual mores. He is said to have asked her whether adolescent troubles were peculiar to Western culture - how did young girls react to the constraints of custom, was it true that primitive girls were excessively bashful, did they develop crushes and other forms of romantic love? It sounds more like what his student told him she intended to study and clearly, even at that youthful age, she was not one to be easily diverted from her purposes.

In 1925 she went to Samoa, chosen by her supervisors as a place where she could be safe under the watchful eye of the United States Department of the Navy. Mary Slessor and Mary Kingsley, much earlier travellers in West Africa, and Edith Durham, travelling in the feuding Balkans, would not have made much of the dangers she faced in the South Pacific. On her return she wrote Coming of Age in Samoa published in 1928, which overnight became a bestseller. Perhaps the grudgingness of colleagues' admiration stemmed from this instant popular success, or perhaps it confirmed a wilful independence and sense 